\title{
Long-term transplant outcomes of donor hearts with left ventricular dysfunction
}

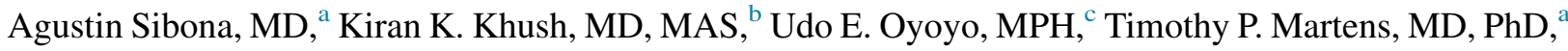 \\ Nahidh W. Hasaniya, MD, PhD, ${ }^{a}$ Anees J. Razzouk, MD, ${ }^{a}$ Leonard L. Bailey, MD, ${ }^{a}$ and \\ David G. Rabkin, MD
}

\section{ABSTRACT}

Objective: Despite small single-center reports demonstrating acceptable outcomes using donor hearts with left ventricular dysfunction, $19 \%$ of potential donor hearts are currently unused exclusively because of left ventricular dysfunction. We investigated modern long-term survival of transplanted donor hearts with left ventricular dysfunction using a large, diverse cohort.

Methods: Using the United Network for Organ Sharing database, we reviewed all adult heart transplants between January 2000 and March 2016. Baseline and postoperative characteristics and Kaplan-Meier survival curves were compared. A covariates-adjusted Cox regression model was developed to estimate posttransplant mortality. To address observed variation in patient profile across donor ejection fraction, a propensity score was built using Cox predictors as covariates in a generalized multiple linear regression model. All the variables in the original Cox model were included. For each recipient, a predicted donor ejection fraction was generated and exported as a new balancing score that was used in a subsequent Cox model. Cubic spline analysis suggested that at most 3 and perhaps no ejection fraction categories were appropriate. Therefore, in $1 \mathrm{Cox}$ model we added donor ejection fraction as a grouped variable (using the spline-directed categories) and in the other as a continuous variable.

Results: A total of 31,712 donor hearts were transplanted during the study period. A total of 742 donor hearts were excluded for no recorded left ventricular ejection fraction, and 20 donor hearts were excluded for left ventricular ejection fraction less than $20 \%$. Donor hearts with reduced left ventricular ejection fraction were from younger donors, more commonly male donors, and donors with lower body mass index than normal donor hearts. Recipients of donor hearts with reduced left ventricular ejection fraction were more likely to be on mechanical ventilation. Kaplan-Meier curves revealed no significant differences in recipient survival up to 15 years of follow-up ( $P=.694$ log-rank test). Cox regression analysis showed that after adjustment for propensity variation, transplant year, and region, ejection fraction had no statistically significant impact on mortality when analyzed as a categoric or continuous variable. Left ventricular ejection fraction at approximately 1 year after transplantation was normal for all groups.

Conclusions: Carefully selected donor hearts with even markedly diminished left ventricular ejection fraction can be transplanted with long-term survival equivalent to normal donor hearts and therefore should not be excluded from

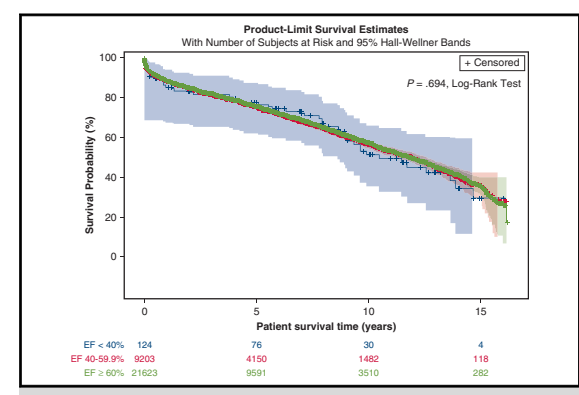

No statistically significant differences in KaplanMeier survival curves were found among groups stratified by LVEF.

Central Message

Hearts with diminished LVEF should not be excluded from consideration of transplantation on the basis of depressed LV function alone.

\section{Perspective}

Despite evidence that approximately $20 \%$ of donor hearts are not used for transplantation exclusively because of depressed LV function, our study finds that donor hearts with even markedly diminished LV function may be transplanted with long-term survival equivalent to hearts with normal LV function.

See Commentaries on pages 1876 1878 , and 1880 .

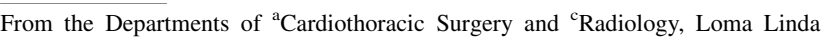
University Medical Center, Loma Linda, Calif; and ${ }^{\mathrm{b}}$ Department of Medicine (Cardiovascular Medicine), Stanford University Medical Center, Palo Alto, Calif. This work was supported in part by Health Resources and Services Administration Contract 234-2005-37011C.

Read at the 43rd Annual Meeting of The Western Thoracic Surgical Association, Colorado Springs, Colorado, June 21-24, 2017.
}

Received for publication June 21, 2017; revisions received July 11, 2018; accepted for publication July 12, 2018; available ahead of print March 8, 2019.

Address for reprints: David G. Rabkin, MD, Coleman Pavilion, Suite 21121, 11175 Campus St, Loma Linda, CA 92354 (E-mail: drabkin@1lu.edu). $0022-5223 / \$ 36.00$

Copyright (c) 2018 by The American Association for Thoracic Surgery https://doi.org/10.1016/j.jtcvs.2018.07.115 


\section{Abbreviations and Acronyms \\ $\mathrm{EF} \quad=$ ejection fraction \\ $\mathrm{LV}=$ left ventricular \\ LVEF $=$ left ventricular ejection fraction \\ UNOS $=$ United Network for Organ Sharing}

Scanning this QR code will take you to the article title page to access supplementary information.

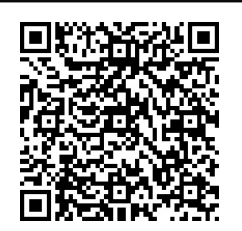

consideration on the basis of depressed left ventricular ejection fraction alone. Functional recovery of even the most impaired donor hearts in this study suggests that studies of left ventricular function in the setting of brain death should be interpreted cautiously. ( $\mathrm{J}$ Thorac Cardiovasc Surg 2019;157:1865-75)

Transplant rates have remained static over the past 15 years at approximately 2000 per year in the United States, ${ }^{1}$ and donor use rates are trending downward. ${ }^{2}$ This has provoked recent reexamination of donor hearts previously excluded from consideration, including use of hearts with a history of resuscitated cardiac arrest ${ }^{3,4}$ and hearts from older donors. ${ }^{5}$ We sought to examine another source of underused donor hearts: those with diminished left ventricular (LV) function. Among the reasons that hearts are declined for transplantation, ventricular dysfunction (often a sequel of the pathophysiologic environment caused by brain death) is among the most common and potentially tractable. Previous work from our group has documented that $19 \%$ of potential donor hearts ( $>1300$ hearts per year) are not accepted for transplantation based entirely on LV dysfunction without evidence of structural disease. ${ }^{6}$ This figure has not been affected by somewhat small, mostly singlecenter clinical studies ${ }^{7-9}$ demonstrating equivalent shortand medium-term outcomes of dysfunctional donor hearts when compared with donor hearts with normal LV function or by experimental studies demonstrating functional resuscitation of hearts damaged by the pathophysiology of brain death. ${ }^{10,11}$ Brain death has been associated not only with impaired donor organ function, an effect that is pronounced in the heart, but also with postoperative complications, including primary graft dysfunction, increased immunogenicity resulting in a higher incidence of both acute and chronic rejection, and worse long-term outcomes. ${ }^{12,13}$ The mechanism of brain death-induced ventricular dysfunction is not well understood and likely multifactorial. Ischemic injury, ${ }^{14}$ direct catecholamine or cytokine-induced myocardial injury, ${ }^{11,15}$ and impaired B-adrenergic receptor signaling ${ }^{16}$ have all been implicated. Although both regional and global LV dysfunction are common in the setting of brain death, neither is correlated with pathologic changes, indicating that the dysfunction is

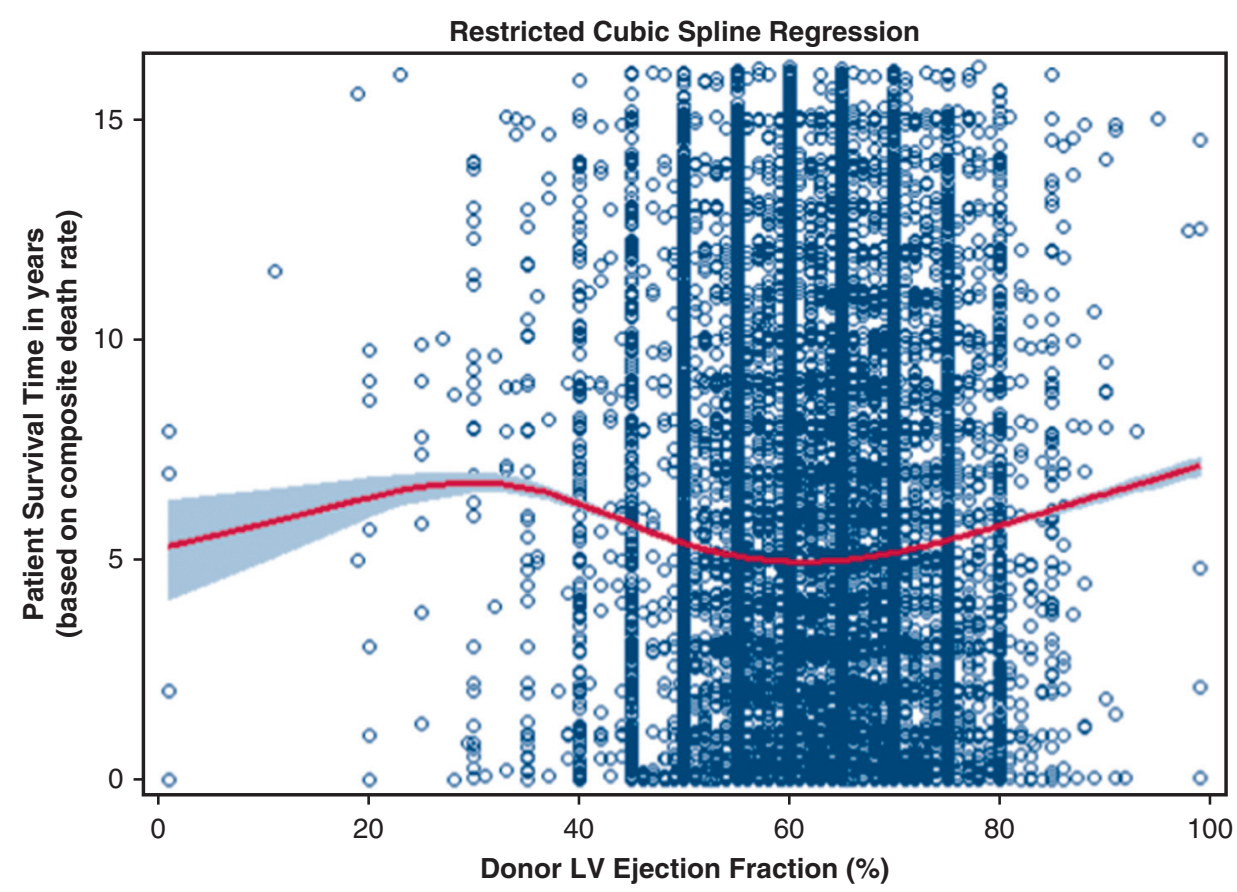

FIGURE 1. Univariate, restricted cubic spline regression using a least-squares model between donor LVEF and survival. $L V$, Left ventricular. 
TABLE 1. Comparison of baseline heart donor characteristics

\begin{tabular}{|c|c|c|c|c|}
\hline & Group $1(n=124)$ & Group $2(n=9203)$ & Group $3(n=21,623)$ & $P$ value \\
\hline Age* $^{*}$ & $21.0(13.0,17.0,28.0,43.0)$ & $28.0(16.0,21.0,39.0,52.0)$ & $30.0(16.0,22.0,42.0,53.0)$ & $<.001$ \\
\hline Gender $(\%)$ & & & & $<.001$ \\
\hline Male & 76.6 & 73.2 & 69.8 & \\
\hline Female & 23.4 & 26.8 & 30.2 & \\
\hline \multicolumn{5}{|l|}{ Race $(\%)$} \\
\hline White & 75.0 & 66.7 & 66.6 & .002 \\
\hline Black & 16.1 & 15.3 & 14.1 & \\
\hline Hispanic & 8.87 & 15.3 & 16.2 & \\
\hline Asian & 0.00 & 1.31 & 1.82 & \\
\hline Indigenous $\dagger$ & 0.00 & 0.61 & 0.69 & \\
\hline Multiracial & 0.00 & 0.67 & 0.57 & \\
\hline Unknown & 0.00 & 0.05 & 0.01 & \\
\hline Body mass index $\ddagger$ & $23.7(18.3,21.6,26.8,33.5)$ & $25.4(19.6,22.7,29.1,36.7)$ & $26.0(19.7,23.1,29.8,37.7)$ & $<.001$ \\
\hline \multicolumn{5}{|l|}{ Cause of death $(\%)$} \\
\hline Anoxia & 19.4 & 17.3 & 16.2 & $<.001$ \\
\hline Stroke & 12.9 & 20.7 & 24.5 & \\
\hline Head trauma & 66.1 & 59.3 & 56.5 & \\
\hline Brain tumor & 0.00 & 0.68 & 0.86 & \\
\hline Other & 1.61 & 2.08 & 1.88 & \\
\hline Inotropes at procurement $(\%)$ & 51.7 & 53.5 & 51.8 & .091 \\
\hline Triiodothyronine at procurement & 4.03 & 1.96 & 1.40 & $<.001$ \\
\hline Ischemic time $\S$ & $3.23(1.55,2.47,3.77,4.60)$ & $3.13(1.53,2.42,3.82,4.85)$ & $3.20(1.57,2.48,3.87,4.95)$ & .211 \\
\hline LVEF $\|$ & $33.0(19.0,30.0,35.0,37.0)$ & $55.0(45.0,51.0,55.0,58.0)$ & $65.0(60.0,60.0,70.0,75.0)$ & $<.001$ \\
\hline
\end{tabular}

$L V E F$, Left ventricular ejection fraction. *Age is reported as median years with 5th, 25th, 75th, and 95th percentiles. $\dagger$ American Indian, Alaska Native, or Native Hawaiian/Other Pacific Islander. $\ddagger$ Body mass index is reported as median $\mathrm{kg} / \mathrm{m}^{2}$ with 5 th, 25 th, 75 th, and 95 th percentiles. $§$ Ischemic time is reported as median hours with 5 th, 25 th, 75 th, and 95 th percentiles. ||LVEF is reported as median $\%$ with 5 th, 25 th, 75 th, and 95 th percentiles.

irreversible. ${ }^{17,18}$ Given the experimental and available clinical evidence supporting the possibility of functional resuscitation of donor hearts with impaired ventricular function in the context of brain death, we believed further investigation was warranted. The current study is an effort to provide more long-term outcome data of donor hearts with LV dysfunction in the modern era of heart transplantation and determine whether consideration of expansion of the donor pool to include some of these organs is appropriate.

\section{MATERIALS AND METHODS}

Our study design was submitted to the Institutional Review Board at Loma Linda University Medical Center, which determined that the study did not meet the definition of human subject research because it did not involve identifiable information, no data or specimens were collected, and there was no direct intervention or interaction. Therefore, the Institutional Review Board decided our study did not require review or approval.

All isolated, adult (recipient aged $\geq 18$ years), first-time heart transplants in the United States between January 1, 2000, and March 31, 2016, were analyzed. Data on donor hearts and post-transplant outcomes were obtained from the United Network for Organ Sharing (UNOS) as the contractor for the Organ Procurement and Transplantation Network provided by way of Standard Transplant Analysis and Research files. Hearts that were transplanted in conjunction with other organs were excluded from this analysis. This work was supported in part by Health
Resources and Services Administration Contract 234-2005-37011C. The content is the responsibility of the authors alone and does not necessarily reflect the views or policies of the Department of Health and Human Services, nor does mention of trade names, commercial products, or organizations imply endorsement by the US Government.

Donor hearts with left ventricular ejection fraction (LVEF) less than $20 \%$ were excluded from the study because we found the values to be implausible. Donor hearts without recorded LVEF were also excluded. The overwhelming majority of LVEF calculations were made by echocardiogram $(95.1 \%)$, although left ventriculogram during left heart catheterization was used in $2.5 \%$ of cases and multi-gated acquisition scan was used in $0.03 \%$. Baseline characteristics of both donor hearts and recipients were compared, as were recipient postoperative complications and overall survival.

\section{Statistical Analysis}

All data were analyzed with SAS 9.4 (SAS Institute Inc, Cary, NC). Kolmogorov-Smirnov analysis demonstrated that continuous variables were not normally distributed; therefore, data are reported as median with selected percentiles (5th, 25th, 75th, and 95th) above and below the median and compared using the Kruskal-Wallis test. The chi-square test was used to compare categoric variables. All reported $P$ values were 2 sided. A univariate, restricted, cubic spline regression was performed using a least-squares model between donor LVEF and survival. We based the smoother on a restricted spline basis with 5 equal knots placed at the $1 / 6$, 2/6, 3/6, 4/6, and 5/6 quantiles. Knots 1 to 5 corresponded with the following donor ejection fractions (EFs): $17.33 \%, 33.67 \%, 50.0 \%$, $66.33 \%$, and $82.67 \%$, respectively. This model indicates a statistically 
TABLE 2. Comparison of baseline heart recipient characteristics

\begin{tabular}{|c|c|c|c|c|}
\hline & Group $1(n=124)$ & Group $2(n=9203)$ & Group $3(n=21,623)$ & $P$ value \\
\hline \multicolumn{5}{|l|}{ Baseline } \\
\hline Age* & $54.5(25.0,44.5,62.0,67.0)$ & $55.0(26.0,46.0,62.0,68.0)$ & $55.0(26.0,46.0,62.0,68.0)$ & .556 \\
\hline Gender $(\%)$ & & & & .341 \\
\hline Male & 74.2 & 75.8 & 74.8 & \\
\hline Female & 25.8 & 24.2 & 25.2 & \\
\hline \multicolumn{5}{|l|}{ Race $(\%)$} \\
\hline White & 71.8 & 70.6 & 70.2 & .006 \\
\hline Black & 16.1 & 19.2 & 17.9 & \\
\hline Hispanic & 10.5 & 6.6 & 7.8 & \\
\hline Asian & 1.61 & 2.54 & 2.88 & \\
\hline Indigenous & 0.00 & 0.52 & 0.71 & \\
\hline Multiracial & 0.00 & 0.48 & 0.52 & \\
\hline Body mass index $\dagger$ & $26.5(18.6,22.7,29.5,33.2)$ & $26.5(19.5,23.4,29.9,35.3)$ & $26.6(19.5,23.4,30.2,35.3)$ & .983 \\
\hline Ventilator $\ddagger$ & 4.03 & 1.52 & 1.64 & $<.001$ \\
\hline $\mathrm{ECMO}_{\ddagger}^{\dagger}$ & 0.81 & 0.55 & .59 & .681 \\
\hline $\operatorname{LVAD}_{\dagger}^{\dagger}$ & 9.21 & 13.5 & 14.0 & .115 \\
\hline Inotropes $\ddagger$ & 54.7 & 43.5 & 41.7 & $<.001$ \\
\hline Total days on waiting list $\S$ & $81.5(4,22.5,232.5,810)$ & $89(4,26,251,830)$ & $89(4,27,252,853)$ & .024 \\
\hline Days status $1 \mathrm{~A} \S$ & $15(1,6,35,107)$ & $21(0,0,28,98)$ & $21(2,8,40,133)$ & .441 \\
\hline Days status $1 \mathrm{~B} \S$ & $22.5(2,7,96,282)$ & $49(2,13,136,419)$ & $48(2,13,132,411)$ & .011 \\
\hline Days status $2 \S$ & $115(1.5,25,408,916)$ & $95(3,27,287,940)$ & $96(3,26,287,928)$ & .009 \\
\hline \multicolumn{5}{|l|}{ Postoperative } \\
\hline ECMO at $72 \mathrm{~h}(\%)$ & 0.81 & 0.55 & 0.59 & .681 \\
\hline Length of stay $\S$ & $13(7,10,24,83)$ & $14(7,10,22,53)$ & $14(7,10,21,53)$ & $<.001$ \\
\hline New dialysis (\%) & 9.68 & 10.35 & 10.19 & $<.001$ \\
\hline Pacemaker (\%) & 3.23 & 3.10 & 3.50 & $<.001$ \\
\hline New stroke $(\%)$ & 0.00 & 2.48 & 2.39 & $<.001$ \\
\hline Treated for rejection in $1 \mathrm{y}(\%)$ & 20.16 & 19.88 & 19.76 & $<.001$ \\
\hline LVEF at $1 \mathrm{y} \|$ & $60(45,55,64,70)$ & $60(45,55,65,70)$ & $60(50,55,65,71)$ & $<.001$ \\
\hline
\end{tabular}

$E C M O$, Extracorporeal membrane oxygenation; $L V A D$, left ventricular assist device; $L V E F$, left ventricular ejection fraction. *Age is reported as median years with 5th, 25th, 75th, and 95 th percentiles. $\dagger$ Body mass index is reported as median $\mathrm{kg} / \mathrm{m}^{2}$ with 5 th, 25 th, 75th, and 95th percentiles. $\ddagger$ At time of transplant (\%). §Median days with 5th, 25th, 75th, and 95 th percentiles. $\|$ LVEF reported as median percent with 5th, 25th, 75th, and 95th percentiles.

significant fit $(\mathrm{F}=22.60, P<.0001)$ with Knot 5 being statistically different from Knot $2(P=.011)$, Knot $3(P=.006)$, and Knot 4 $(P=.040)$. Knot 1 was not identified as being statistically different from Knot $5(P=.269)$. Because of the appearance of the cubic spline curve (Figure 1), we thought that at most 3 groups (group 1: $\mathrm{EF}<40$, group 2: EF $40-\leq 60$, and group 3: $\mathrm{EF}>60$ ) and perhaps no groups would be most appropriate.

Kaplan-Meier curves with donor hearts grouped by LV function, as indicated by the spine analysis, were generated to compare the overall survival of the groups. Given the imbalance in sample number and resultant events among the groups, Kaplan-Meier curves were truncated for less than 10 patients at risk in an attempt to attenuate wide confidence intervals.

A covariates-adjusted Cox regression model with robust standard errors was developed to estimate post-transplant mortality hazard ratios with $95 \%$ confidence interval for LV dysfunction. Covariates considered for inclusion in the model included all available donor and recipient data (Tables 1 and 2), as well as UNOS region and transplant era (we divided the 17 years of the study into 4 different periods: 2000-2003, 2004-2007, 2008-2011, and 2012-2016). The Cox model assumes that hazard ratios should be constant over time (proportional hazards). We assessed each categoric covariate for whether the assumption of proportional hazards was reasonable. Where nonproportional hazards were present, we considered a stratified model. We assessed proportional hazards with a plot of standardized score residuals over time. We concluded that if the residuals were unusually large at any time point, the proportional hazards assumption was violated. In that case, we produced plots of randomly generated score processes to allow for graphic assessment of the observed residuals. To address observed variation in patient profile across donor EF, a propensity score was built using Cox predictors as covariates in a generalized multiple linear regression model. ${ }^{19}$ All the variables in the original Cox model were included. For each recipient, a predicted donor EF was generated and exported as a new balancing score that was used in a subsequent Cox model. As noted earlier, Cubic spline analysis suggested that at most 3 groups and perhaps no groups were appropriate. We evaluated donor EF separately as a grouped variable and then as a continuous variable in the Cox model.

\section{RESULTS}

During the study period, 31,712 isolated, first-time heart transplants were performed in recipients older than 18 years of age. Of these, 124 were in group $1(\mathrm{EF}<40 \%), 9203$ were in group 2 (EF 40\%-59.9\%), and 21,623 were in group $3(\geq 60 \%)$. Median LVEF for groups 1 to 3 was $33.0 \%, 55.0 \%$, and $65.0 \%$, respectively $(P<.001)$. A total of 742 donor hearts were excluded for not having a recorded 


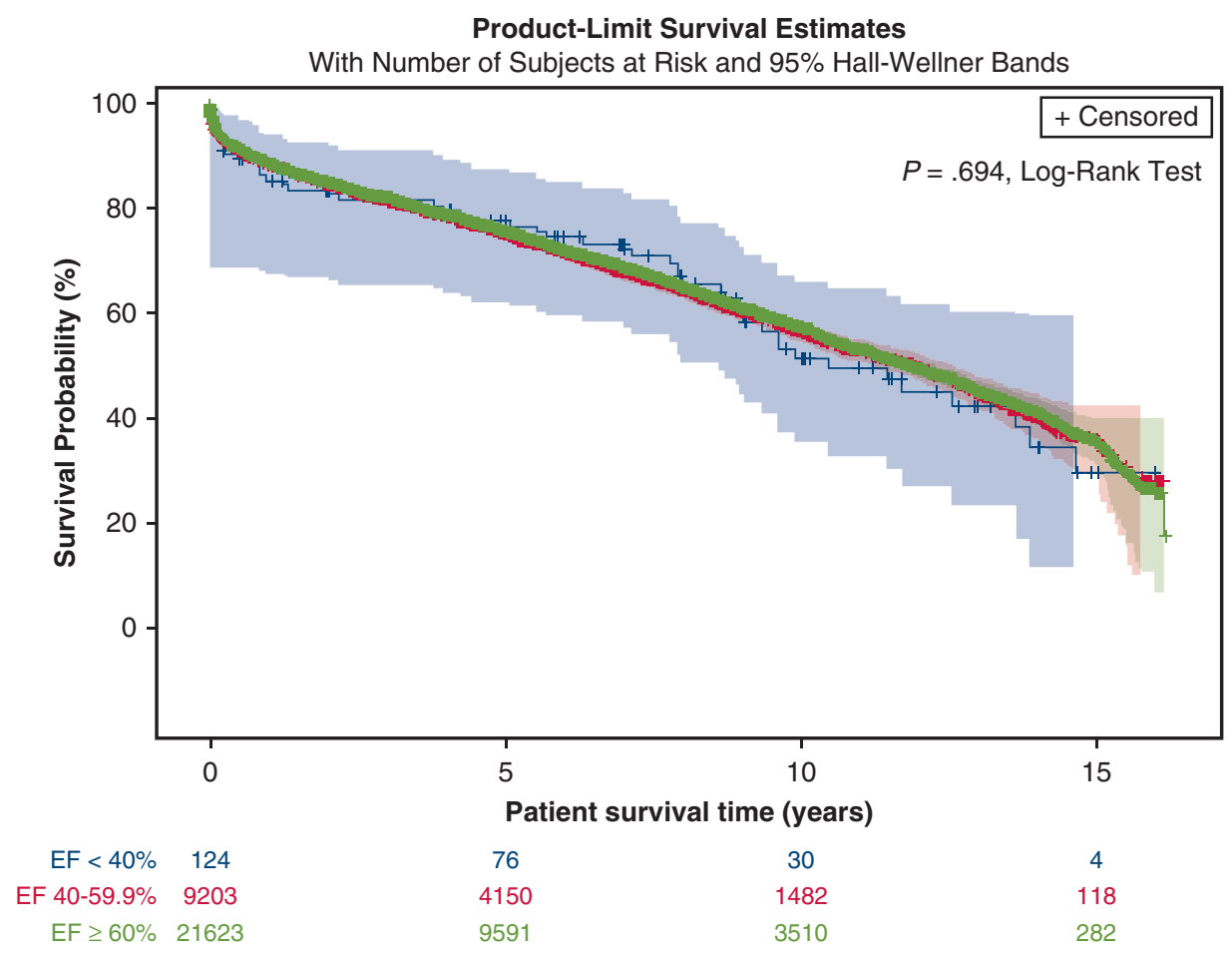

FIGURE 2. Kaplan-Meier survival curves with $95 \%$ Hall-Wellner bands. No significant differences in post-transplant Kaplan-Meier survival curves were found among groups stratified by LVEF. LVEF less than $40 \%$ blue, LVEF $40 \%$ to $59.9 \%$ red, LVEF $60 \%$ or greater green. $E F$, Ejection fraction.

LVEF, and 20 donor hearts were excluded because of LVEF less than 20\%. Mean follow-up was $1890 \pm 1564$ (standard deviation) days.

Comparison of baseline heart donor characteristics is shown in Table 1. Median age varied inversely with ventricular function, and differences were statistically significant

TABLE 3. Hearts transplanted in each left ventricular ejection fraction group by United Network for Organ Sharing region

\begin{tabular}{|c|c|c|c|c|}
\hline & Group 1 & Group 2 & Group 3 & $\begin{array}{c}P \\
\text { value }\end{array}$ \\
\hline $\begin{array}{l}\text { UNOS region }(\% \text { of } \\
\text { total transplants } \\
\text { performed })\end{array}$ & & & & $<.001$ \\
\hline $1(3.8 \%)$ & $12(1.0 \%)$ & $384(32.2 \%)$ & $778(65.3 \%)$ & \\
\hline $2(13.3 \%)$ & $24(0.57 \%)$ & $1348(32.1 \%)$ & $2680(63.7 \%)$ & \\
\hline $3(12.1 \%)$ & $5(0.13 \%)$ & $1105(28.9 \%)$ & $2652(69.4 \%)$ & \\
\hline $4(10.7 \%)$ & $10(0.29 \%)$ & $979(28.8 \%)$ & $2392(70.3 \%)$ & \\
\hline $5(15.8 \%)$ & $16(0.32 \%)$ & $1031(20.6 \%)$ & $3923(78.2 \%)$ & \\
\hline $6(3.0 \%)$ & $0(0.0 \%)$ & $193(20.0 \%)$ & $761(79.0 \%)$ & \\
\hline $7(9.3 \%)$ & $11(0.37 \%)$ & $797(27.1 \%)$ & $1905(64.8 \%)$ & \\
\hline $8(5.5 \%)$ & $3(0.17 \%)$ & $483(27.5 \%)$ & $1256(71.4 \%)$ & \\
\hline $9(6.7 \%)$ & $14(0.66 \%)$ & $739(34.9 \%)$ & $1297(61.2 \%)$ & \\
\hline $10(8.7 \%)$ & $13(0.47 \%)$ & $877(31.9 \%)$ & $1791(65.2 \%)$ & \\
\hline $11(11.2 \%)$ & $16(0.45 \%)$ & $1285(36.0 \%)$ & $2213(62.1 \%)$ & \\
\hline
\end{tabular}

UNOS, United Network for Organ Sharing.
$(P<.001)$. Group 3 had the highest proportion of female donors $(30.2 \%)$, and group 1 had the lowest $(23.4 \%)$ $(P<.001)$. Donors in group 1 were significantly more likely to be white $(P=.002)$. Group 1 had the lowest median body mass index at $23.7 \mathrm{~kg} / \mathrm{m}^{2}$, whereas group 3 had the highest at $26.0 \mathrm{~kg} / \mathrm{m}^{2}(P<.001)$. Donors in group 1 were more likely to have died of anoxia and head trauma and less likely to have died of stroke $(P<.001)$. They were also more likely to be on triiodothyronine at the time of procurement. Comparison of recipient characteristics is shown in Table 2. There were no statistically significant differences in median age, gender, median body mass index, or use of mechanical circulatory support before transplant. Recipients of donor hearts from group 1 were significantly more likely to be on ventilator and inotropic support at the time of transplant.

Kaplan-Meier survival curves demonstrated no statistically significant differences in survival among the 3 groups at up to 15 years of follow-up $(P=.694)$ (Figure 2). There were no significant differences in the need for extracorporeal membrane oxygenation at 72 hours after transplant, and differences in length of stay, new indication for dialysis, new pacemaker, and treatment for rejection within 1 year of transplant were not clinically significant. Differences in LVEF at approximately 1 year after transplantation were statistically but 
TABLE 4. Cox regression hazard ratios and confidence intervals using left ventricular ejection fraction as a categoric variable

\begin{tabular}{|c|c|c|c|c|c|c|}
\hline Parameter & Parameter estimate & Standard error & Chi-square & $P$ value & HR & $95 \%$ Wald confidence limits \\
\hline Group 2 (EF 40\%-59.9\%) & 0.091 & 0.295 & 0.095 & .758 & $1.095^{*}$ & $0.615-1.951$ \\
\hline Group $1(\mathrm{EF}<40 \%)$ & 0.031 & 0.052 & 0.353 & .553 & $1.031 *$ & $0.932-1.142$ \\
\hline Age recipient & 0.015 & 0.002 & 64.45 & $<.001$ & $1.015 \dagger$ & $1.011-1.019$ \\
\hline Age donor & 0.003 & 0.002 & 2.491 & .115 & $1.003 \dagger$ & $0.999-1.007$ \\
\hline Female gender & 0.027 & 0.053 & 0.250 & .617 & 1.027 & $0.925-1.140$ \\
\hline \multicolumn{7}{|l|}{ Race/ethnicity recipient } \\
\hline Black & 0.096 & 0.055 & 2.996 & .084 & $1.101 \ddagger$ & $0.987-1.227$ \\
\hline Hispanic & 0.013 & 0.095 & 0.019 & .892 & $1.013 \ddagger$ & $0.841-1.220$ \\
\hline Asian & 0.335 & 0.186 & 3.256 & .071 & $1.399 \ddagger$ & $0.971-2.013$ \\
\hline American Indian & -0.067 & 0.417 & 0.026 & .873 & $0.935 \ddagger$ & $0.413-2.117$ \\
\hline Native Hawaiian & -0.428 & 0.344 & 1.543 & .214 & $0.652 \ddagger$ & $0.332-1.280$ \\
\hline Multiracial & 0.021 & 0.295 & 0.005 & .944 & $1.021 \ddagger$ & $0.573-1.818$ \\
\hline \multicolumn{7}{|l|}{ Race/ethnicity donor } \\
\hline Black & 0.061 & 0.067 & 0.821 & .365 & $1.063 \ddagger$ & $0.932-1.212$ \\
\hline Hispanic & 0.096 & 0.072 & 1.763 & .184 & $1.101 \ddagger$ & $0.955-1.268$ \\
\hline Asian & 0.367 & 0.213 & 2.963 & .085 & $1.443 \ddagger$ & $0.950-2.192$ \\
\hline American Indian & -0.447 & 0.308 & 2.105 & .147 & $0.640 \ddagger$ & $0.350-1.170$ \\
\hline Native Hawaiian & -0.334 & 0.715 & 0.219 & .640 & $0.716 \ddagger$ & $0.176-2.908$ \\
\hline Multiracial & 0.164 & 0.325 & 0.254 & .614 & $1.178 \ddagger$ & $0.623-2.229$ \\
\hline BMI recipient & 0.009 & 0.005 & 3.375 & .066 & 1.009 & $0.999-1.018$ \\
\hline Days on wait list & 0.000 & 0.000 & 0.045 & .833 & 1.000 & $1.000-1.000$ \\
\hline \multicolumn{7}{|l|}{ UNOS region } \\
\hline 1 & 0.759 & 0.243 & 9.761 & .002 & $2.135 \S$ & $1.327-3.437$ \\
\hline 2 & 0.627 & 0.204 & 9.412 & .002 & $1.873 \S$ & $1.254-2.796$ \\
\hline 3 & 0.557 & 0.197 & 7.946 & .005 & $1.745 \S$ & $1.185-2.569$ \\
\hline 4 & 0.429 & 0.187 & 5.281 & .022 & $1.536 \S$ & $1.065-2.215$ \\
\hline 5 & 0.038 & 0.174 & 0.048 & .827 & $1.039 \S$ & $1.739-1.461$ \\
\hline 7 & 0.572 & 0.203 & 7.983 & .005 & $1.772 \S$ & $1.192-2.636$ \\
\hline 8 & 0.509 & 0.196 & 6.737 & .009 & $1.664 \S$ & $1.133-2.445$ \\
\hline 9 & 0.681 & 0.220 & 9.585 & .002 & $1.976 \S$ & $1.284-3.041$ \\
\hline 10 & 0.780 & 0.220 & 12.54 & $<.001$ & $2.182 \S$ & $1.417-3.360$ \\
\hline 11 & 1.098 & 0.225 & 23.81 & $<.001$ & $2.998 \S$ & $1.929-4.660$ \\
\hline \multicolumn{7}{|l|}{ Era } \\
\hline 2000-2003 & 0.16909 & 0.03706 & 20.814 & $<.001$ & $1.184 \|$ & $1.101-1.273$ \\
\hline 2004-2007 & 0.13619 & 0.03705 & 13.508 & .0002 & $1.146 \|$ & $1.066-1.232$ \\
\hline 2008-2011 & 0.03944 & 0.03818 & 1.0668 & .3017 & $1.040 \|$ & $0.965-1.121$ \\
\hline Propensity score & 0.154 & 0.034 & 19.97 & $<.001$ & $1.166 \rrbracket$ & $1.090-1.248$ \\
\hline Ischemic time (h) & 0.068 & 0.022 & 9.245 & .002 & 1.070 & $1.024-1.118$ \\
\hline Length of stay (d) & -0.001 & 0.001 & 0.372 & .542 & 0.999 & $0.997-1.001$ \\
\hline
\end{tabular}

HR, Hazard ratio; $E F$, ejection fraction; $B M I$, body mass index; UNOS, United Network for Organ Sharing. *HR compared with group 1 (EF $>60 \%)$. $\dagger \mathrm{HR}$ reflects the effect of a 1 -year change in age. $\ddagger$ HR compared with white ethnicity. $\S$ HR compared with UNOS region 6 . ||HR compared with era 2012-2016. $₫$ HR reflects 1 -unit increase in the conditional probability of donor ejection fraction group given individual covariates.

not clinically significant because all LVEF groups had normalized (Table 2).

Distribution of transplants across donor heart function groups varied significantly among UNOS regions (Table 3); however, no trend emerged between regional volume and willingness to transplant hearts with LV dysfunction. In multivariate analysis, UNOS region did emerge as an independent predictor of mortality (Tables 4 and 5), with UNOS region 6 demonstrating best overall survival.
Likewise, transplant era emerged as an independent predictor of survival (Tables 4 and 5), with the most recent era (20122016) having the best overall survival.

Cox regression analysis using EF as a categoric variable (Table 4) and as a continuous variable (Table 5) showed that after adjustment for propensity variation, transplant year, and transplant region, EF had no statistically significant impact on mortality. 
TABLE 5. Cox regression hazard ratios and confidence intervals using left ventricular ejection fraction as a continuous variable

\begin{tabular}{|c|c|c|c|c|c|c|}
\hline Parameter & Parameter estimate & Standard error & Chi-square & $P$ value & HR & $95 \%$ Wald confidence limits \\
\hline Ejection fraction & -0.001 & 0.003 & 0.171 & .679 & $0.999 *$ & $0.993-1.005$ \\
\hline Age recipient & 0.015 & 0.002 & 64.48 & $<.001$ & $1.015 \dagger$ & $1.011-1.019$ \\
\hline Age donor & 0.003 & 0.002 & 2.491 & .123 & $1.003 \dagger$ & $0.999-1.007$ \\
\hline Female gender & 0.027 & 0.053 & 0.250 & .620 & 1.027 & $0.925-1.140$ \\
\hline \multicolumn{7}{|c|}{ Race/ethnicity recipient } \\
\hline Black & 0.096 & 0.055 & 2.996 & .084 & $1.101 \ddagger$ & $0.987-1.227$ \\
\hline Hispanic & 0.013 & 0.095 & 0.019 & .886 & $1.013 \ddagger$ & $0.841-1.220$ \\
\hline Asian & 0.335 & 0.186 & 3.256 & .075 & 1.399 & $0.971-2.013$ \\
\hline American Indian & -0.067 & 0.417 & 0.026 & .875 & $0.935 \ddagger$ & $0.413-2.117$ \\
\hline Native Hawaiian & -0.428 & 0.344 & 1.543 & .214 & $0.652 \ddagger$ & $0.332-1.280$ \\
\hline Multiracial & 0.021 & 0.295 & 0.005 & .946 & $1.021 \ddagger$ & $0.573-1.818$ \\
\hline \multicolumn{7}{|l|}{ Race/ethnicity donor } \\
\hline Black & 0.060 & 0.067 & 0.821 & .370 & $1.063 \ddagger$ & $0.932-1.212$ \\
\hline Hispanic & 0.097 & 0.072 & 1.763 & .180 & $1.101 \ddagger$ & $0.955-1.268$ \\
\hline Asian & 0.364 & 0.213 & 2.963 & .088 & $1.443 \ddagger$ & $0.950-2.192$ \\
\hline American Indian & -0.440 & 0.308 & 2.105 & .153 & $0.640 \ddagger$ & $0.350-1.170$ \\
\hline Native Hawaiian & -0.343 & 0.715 & 0.219 & .632 & 0.716 & $0.176-2.908$ \\
\hline Multiracial & 0.165 & 0.325 & 0.254 & .613 & 1.178 & $0.623-2.229$ \\
\hline BMI recipient & 0.009 & 0.005 & 3.375 & .067 & 1.009 & $0.999-1.018$ \\
\hline Days on wait list & 0.000 & 0.000 & 0.045 & .834 & 1.000 & $1.000-1.000$ \\
\hline \multicolumn{7}{|l|}{ UNOS region } \\
\hline 1 & 0.755 & 0.243 & 9.761 & .002 & $2.135 \S$ & $1.327-3.437$ \\
\hline 2 & 0.623 & 0.204 & 9.412 & .002 & $1.873 \S$ & $1.254-2.796$ \\
\hline 3 & 0.552 & 0.197 & 7.946 & .005 & $1.745 \S$ & $1.185-2.569$ \\
\hline 4 & 0.426 & 0.187 & 5.281 & .023 & $1.536 \S$ & $1.065-2.215$ \\
\hline 5 & 0.033 & 0.174 & 0.048 & .847 & $1.039 \S$ & $1.739-1.461$ \\
\hline 7 & 0.558 & 0.203 & 7.983 & .005 & $1.772 \S$ & $1.192-2.636$ \\
\hline 8 & 0.506 & 0.196 & 6.737 & .010 & $1.664 \S$ & $1.133-2.445$ \\
\hline 9 & 0.677 & 0.220 & 9.585 & .002 & $1.976 \S$ & $1.284-3.041$ \\
\hline 10 & 0.778 & 0.220 & 12.54 & $<.001$ & $2.182 \S$ & $1.417-3.360$ \\
\hline 11 & 1.095 & 0.225 & 23.81 & $<.001$ & $2.998 \S$ & $1.929-4.660$ \\
\hline \multicolumn{7}{|l|}{ Era } \\
\hline 2000-2003 & 0.16909 & 0.03706 & 20.814 & $<.001$ & $1.184 \|$ & $1.101-1.273$ \\
\hline 2004-2007 & 0.13619 & 0.03705 & 13.508 & .0002 & $1.146 \|$ & $1.066-1.232$ \\
\hline 2008-2011 & 0.03944 & 0.03818 & 1.0668 & .3017 & $1.040 \|$ & $0.965-1.121$ \\
\hline Propensity score & 0.153 & 0.034 & 19.85 & $<.001$ & $1.166 \rrbracket$ & $1.090-1.248$ \\
\hline Ischemic time (h) & 0.068 & 0.022 & 9.245 & .002 & 1.070 & $1.025-1.118$ \\
\hline Length of stay (d) & -0.001 & 0.001 & 0.373 & .541 & 0.999 & $0.997-1.001$ \\
\hline
\end{tabular}

$H R$, Hazard ratio; BMI, body mass index; UNOS, United Network for Organ Sharing. *HR reflects a $1 \%$ change in ejection fraction. †HR for age reflect the effect of a 1-year change in age. †HR compared with white ethnicity. §HR compared with UNOS region 6. |HR compared with era 2012-2016. $₫$ HR reflects 1-unit increase in the conditional probability of donor ejection fraction group given individual covariates.

\section{DISCUSSION}

Our study provides modern, robust, long-term data on survival of recipients of donor hearts with suboptimal LV systolic function and suggests a pathway to explore expansion of the donor pool by reclaiming a portion of the donor pool unused because of poor function. Limitations of our work include those inherent in all retrospective, observational studies and in those dependent on manual data entry. In addition, during the period of study, digitization of echocardiograms became more common, and therefore there was increased ability for transplant centers to review copies of the echocardiogram performed and interpreted at the procurement center. Therefore, there may have been disparities between the EF recorded at the procurement center and the transplant center's cardiologist's or surgeon's interpretation of the same echocardiogram. Furthermore, because only 1 EF is recorded in the UNOS database, it is also possible 


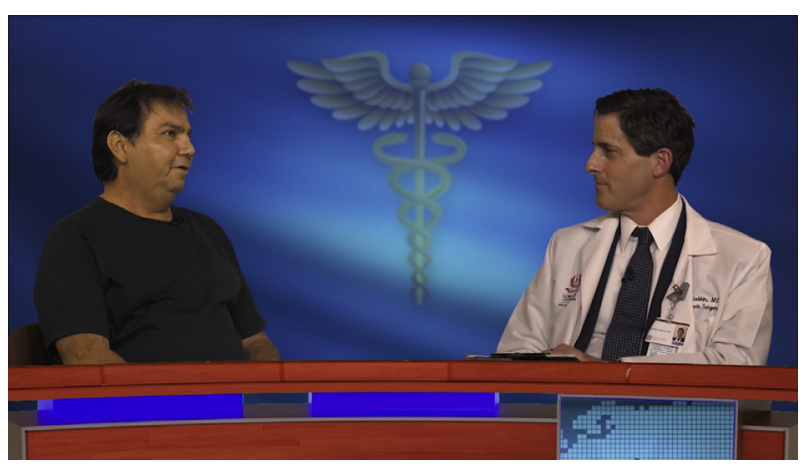

VIDEO 1. Dr David G. Rabkin and the recipient of a donor heart with low LVEF discuss the patient's experiences. Video available at: https://www. jtcvs.org/article/S0022-5223(18)32826-5/fulltext.

that subsequent echocardiograms were performed demonstrating a change in function but not recorded in the UNOS database.

Despite these drawbacks, several useful conclusions emerge. Using a large, contemporary database and a balancing methodology that accounts for baseline differences in donor and recipient characteristics, and looking at $\mathrm{EF}$ as both a categoric variable guided by spline analysis and a continuous variable, we showed that after adjustment for transplant year and transplant region, EF had no statistically significant impact on mortality. At the very least, this should provide reassurance about using donor hearts with LVEF $50 \%$ to $54.9 \%$ and hopefully discourage the surprisingly common practice of nonuse of these hearts based exclusively on the perception that their function is compromised. $^{6}$

Perhaps more compelling than the survival data was the demonstration that ventricular function across all donor heart groups normalized at approximately 1 year (Table 2 and Video 1). This supports prior experimental studies demonstrating functional recovery of hearts damaged by the pathophysiology of brain death after the organ is removed or protected from the hostile environment produced by brain death $^{10,11}$ and suggests that studies of LV function in the setting of brain death should be interpreted cautiously.

Our study demonstrates that reduced LV systolic function alone should not be used as a basis for nonuse. This is a common occurrence. Our group has demonstrated that isolated LV systolic dysfunction is used as the sole explanation for nonuse in $19 \%$ of potential donors whose hearts were declined for transplantation, amounting to approximately 1300 hearts per year. ${ }^{6}$ Of the donor hearts with recorded LVEF included in that study, $60.41 \%$ had LVEF $40 \%$ or greater, included in group 2 or 3 . This represents approximately 785 hearts per year.

After our article had been accepted for presentation, Dr Chen and colleagues ${ }^{20}$ published a study with somewhat different methodology but demonstrating similar results.
They categorized patients into 3 cohorts by donor EF: less than $40 \%$ (reduced $\mathrm{EF}$ ), $40 \%$ to $50 \%$ (borderline $\mathrm{EF}$ ), and $50 \%$ or more (normal EF). Propensity score matching was performed using 1-to-1 matching without replacement to separately compare reduced EF cases with normal EF cases, and borderline EF cases with normal EF cases. Baseline variables with statistically significant differences among the cohorts were chosen for propensity score matching. Using the UNOS database, Chen and colleagues ${ }^{20}$ showed that after matching baseline donor and recipient characteristics, patients who received hearts with "reduced" and "borderline" function had equivalent 1year survival compared with patients who received hearts with LVEF greater than $50 \%$. Our study supports and extends their results to demonstrate equivalent long-term survival of donor hearts with diminished ventricular function.

\section{CONCLUSIONS}

Alternative therapies for patients on the heart transplant waiting list include continued waiting for primary transplant with modern waiting list mortality (or removal from transplant list because of deterioration) for status 1a of $15 \%$ at 180 days,${ }^{21}$ bridge to transplant using an LV assist device with equivalent short-term survival but higher incidence of pretransplant complications (gastrointestinal bleeding, pump thrombosis/failure, LV assist device-related infection, cerebrovascular accident, and development of human leukocyte antigen antibodies) with unclear impact on long-term outcomes and no guarantee of receiving a heart with normal LV function, ${ }^{22-25}$ high-risk conventional surgery for selected patients, ${ }^{26}$ or forgoing these therapies in favor of end-of-life care. ${ }^{27}$ Although even if a large number of donor hearts with reduced ventricular function were used, there would still be a significant disparity between available and needed organs. Given these alternatives, nonuse of donor hearts with diminished LVEF on the basis of depressed function alone may represent a waste of valuable organs for transplantation.

\section{Conflict of Interest Statement}

Authors have nothing to disclose with regard to commercial support.

\section{References}

1. Lund LH, Edwards LB, Kucheryavaya AY, Benden C, Christie JD, Dipchand AI, et al. The registry of the International Society for Heart and Lung Transplantation: thirty-first official adult heart transplant report-2014. J Heart Lung Transplant. 2014;33:996-1008.

2. Khush KK, Zaroff JG, Nguyen J, Menza R, Goldstein BA. National decline in donor heart utilization with regional variability: 1995-2010. Am J Transplant. 2015; $15: 642-9$.

3. Galeone A, Varnous S, Lebreton G, Barreda E, Hariri S, Pavie A, et al. Impact of cardiac arrest resuscitated donors on heart transplant recipients' outcome. J Thorac Cardiovasc Surg. 2017;153:622-30. 
4. Trivedi JR, Gallo M, Slaughter MS. Use of resuscitated donor hearts for transplantation: same results either side of the Atlantic Ocean. J Thorac Cardiovasc Surg. 2017; 154:539.

5. Prieto D, Correlia P, Baptista M, Antunes MJ. Outcome after heart transplantation from older donor age: expanding the donor pool. Eur $J$ Cardiothorac Surg. 2015;47:672-8.

6. Tryon D, Hasaniya NW, Jabo B, Razzouk AJ, Bailey LL, Rabkin DG. Effect of left ventricular dysfunction on utilization of donor hearts. J Heart Lung Transplant. 2018;37:349-57.

7. Smits JM, De Paum M, de Vries E, Rahmel A, Meiser B, Laufer G, et al. Donor scoring system for heart transplantation and the impact on patient survival. J Heart Lung Transplant. 2012;31:387-97.

8. Khush KK, Menza R, Nguyen J, Zaroff JG, Goldstein BA. Donor predictors of allograft utilization and recipient outcomes after heart transplantation. Circ Heart Fail. 2013;6:300-9.

9. Rao SD, Watson A, Lo P, Jabbour A, Hayward CS, Keogh AM, et al. Successful orthotopic heart transplantation using donors with left ventricular systolic dysfunction: Evidence for brain death-induced Takotsubo cardiomyopathy. J Heart Lung Transplant. 2015;34:S71-2.

10. Galinañes M, Hearse DJ. Brain death-induced impairment of cardiac contractile performance can be reversed by explantation and may not preclude the use of the hearts for transplantation. Circ Res. 1992;71:1213-9.

11. Mikhova KM, Don CW, Laflamme M, Kellum JA, Mulligan MS, Verrier ED, et al. Effect of cytokine hemoadsorption on brain death-induced ventricular dysfunction in a porcine model. J Thorac Cardiovasc Surg. 2013;145:215-24.

12. Wilhelm MJ, Pratschke J, Beato F, Taal M, Kusaka M, Hancock WW, et al. Activation of the heart by donor brain death accelerates acute rejection after transplantation. Circulation. 2000;102:2426-33.

13. Pratschke J, Wilhelm MJ, Laskowski I, Kusaka M, Beato F, Tullius SG, et al. Influence of donor brain death on chronic rejection of renal transplants in rats. J Am Soc Nephrol. 2001;12:2474-81.

14. Halejcio-Delophont P, Siaghy EM, Devaux Y, Richoux JP, Bischoff N, Carteaux JP, et al. Consequences of brain death on coronary blood flow and myocardial metabolism. Transplant Proc. 1998:30:2840-1.

15. White M, Wieschmann RJ, Roden RL, Hagan MB, Wollmering MM, Port JD, et al. Cardiac B-adrenergic neuroeffector systems in acute myocardial dysfunction related to brain injury; evidence for catecholamine-mediated myocardial damage. Circulation. 1995;92:2183-9.

16. D'Amico TA, Meyers CH, Koutlas TC, Peterseim DS, Sabiston DC, Van Trigt P, et al. Desensitization of myocardial ß-adrenergic receptors and deterioration of left ventricular function after brain death. J Thorac Cardiovasc Surg. 1995; 110:746-51.

17. Dujardin KS, McCully RB, Wijdicks EFM, Tazelaar HD, Seward JB, McGregor CGA, et al. Myocardial dysfunction associated with brain death: clinical, echocardiographic, and pathologic features. J Heart Lung Transplant. 2001; 20:350-7.

18. Mehra MR, Ventura HO. Brain injury and ventricular dysfunction: insights into reversible heart failure. Congest Heart Fail. 2005;11:99-101.

19. Rosenbaum PR, Rubin DB. The central role of the propensity score in observational studies for causal effects. Biometrika. 1983;70:41-55.

20. Chen CW, Sprys MH, Gaffey AC, Chung JJ, Margulies KB, Acker MA, et al. Low ejection fraction in donor hearts is not directly associated with increased recipient mortality. J Heart Lung Transplant. 2017;36:611-5.

21. Singh TP, Almond CS, Taylor DO, Graham DA. Decline in heart transplant wait list mortality in the United States following broader regional sharing of donor hearts. Circ Heart Fail. 2012;5:249-58.

22. Shah H, Kahanda M, Schilling J, LaRue S, Shuster J, Sitner S. The impact of LVAD complications on short-term outcomes after heart transplantation. J Heart Lung Transplant. 2016;35:S264-5.

23. Drakos SG, Kfoury AG, Kotter JR, Reid BB, Clayson SE, Selzman CH, et al. Prior human leukocyte antigen-allosensitization and left ventricular assist device type affect degree of post-implantation human leukocyte antigen-allosensitization. J Heart Lung Transplant. 2009;28:838-42.

24. Arnaoutakis GJ, George TJ, Kilic A, Weiss ES, Russell SD, Conte JV, et al. Effect of sensitization in US heart transplant recipients bridged with a ventricular assist device: update in a modern cohort. J Thorac Cardiovasc Surg. 2011;142: 1236-45.

25. Bull DA, Reid BB, Selzman CH, Mesley R, Drakos S, Clayson S, et al. The impact of bridge-to-transplant ventricular assist device support on survival after cardiac transplantation. J Thorac Cardiovasc Surg. 2010;140:169-73.
26. Kawajiri J, Manlhiot C, Ross H, Delgado D, Billia F, McDonald M, et al High-risk cardiac surgery as an alternative to transplant or mechanical support in patients with end-stage heart failure. J Thorac Cardiovasc Surg. 2017; 154:517-25.

27. Whellan DJ, Goodlin SJ, Dickinson MG, Heidenreich PA, Jaenicke C, Stough WG, et al. End-of-life care in patients with heart failure. J Card Fail. 2014;20:121-34.

Key Words: heart transplantation, heart donor evaluation, ventricular function

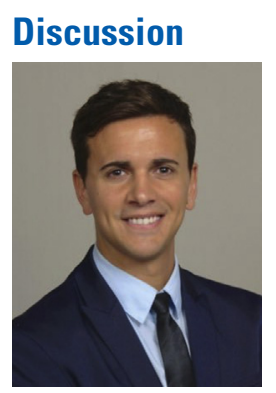

Dr Augustin Sibona (Loma Linda, Calif). [Note-the manuscript has changed substantially in the revision process since this discussion took place.] This recent project is performed by the Department of Cardiothoracic Surgery and Radiology at Loma Linda University Medical Center with the collaboration of the Department of Medicine at Stanford University Medical Center. We have nothing to disclose. End-stage heart failure events occur in people every year, and cardiac transplantation remains the gold standard of care; however, as you see in this graphic, transplant rates have remained static over the past 15 years at 2000 to 2500 per year in the United States. Previous work from our research group has documented that $19 \%$ of the patient donor hearts are not used for transplantation entirely based on left ventricular dysfunction. This pie graph represents the total donor heart pool. Thirty-five percent of the donor hearts are being transplanted; in red, you can appreciate the proportion of hearts not being transplanted entirely based on a low EF, which is 1300 hearts a year. The goals of our project are to provide robust and long-term outcome data of adult hearts with diminished left ventricular function and determine whether expansion of the donor pool is appropriate. Data were obtained from the UNOS database. All isolated adult heart transplants in the United States between January 1, 2000, and March 31, 2016, were included. For the purposes of our study, the definition of a normal EF is more than $55 \%$, and for exclusion criteria we have hearts transplanted along with other organs, hearts with an EF less than $20 \%$ in the pediatric population.

The donor hearts were divided into 5 groups: (1) included hearts with an EF greater than $55 \%$; (2) hearts with EF between $50 \%$ and $54.9 \%$; (3) EF between $40 \%$ and $49.9 \%$; (4) EF between $30 \%$ and $39.9 \%$; and (5) EF between $20 \%$ and $29.9 \%$. Baseline characteristics, postoperative length of stay, and Kaplan-Meier survival curves were compared. This is a brief summary of the analysis. During the study period, 31,979 hearts were transplanted, 
and we excluded 279 hearts for not having EF recorded and 788 hearts for having EF of less than $20 \%$, so we included 30,942 hearts. Of these, 28,044 were included in group 1 , 2187 were included in group 2, 595 were included in group 3, 95 hearts were included in group 4, and 21 hearts were included in group 5. The median follow-up was 1513 days. Mean age varied inversely with left ventricular function and differences were statistically significant. Group 1 had the highest proportion of female donors, and group 4 had the lowest. The mean left ventricular EF was $63 \%$, $50 \%, 44 \%, 34 \%$, and $23 \%$ for groups 1 through 5 , respectively, and there were no statistically significant differences in cause of death, donor race, or cold ischemic times among the study groups comparisons of differences in baseline recipient characteristics. These are the KaplanMeier survival curves for each of the 5 groups, with survivor probability on the Y-axis and post-transplant survival in days on the $\mathrm{X}$-axis. There were no statistically significant differences between the groups. The differences in the mean postoperative length of stay were statistically significant with length of stay increasing with decreasing ventricular function except for group \%, which had the lowest length of stay likely due to high perioperative mortality. Cox regression analysis demonstrated that left ventricular EF is a significant predictor of mortality after adjustment for donor and recipient age. Using group 1 as a reference, recipients of hearts from group 3 and group 5 were found to have significantly higher mortality. However, group 2 is a large cohort study with survival indistinguishable from group 1. Group 3 showed equivalent postoperative length of stay and equivalent survival on univariate analysis, but diminished survival on multivariate analysis, which suggested that good results were achieved through a careful selection of the hearts. Group 4 showed equivalent survival on both univariate and multivariate analyses, although with increased postoperative length of stay. Group 5 is a small cohort with high perioperative mortality and a trend toward reduced survival after 3000 days on univariate analysis. There was an inverse relationship between donor age and left ventricular function and multivariate analysis suggests that transplant teams were more inclined to take donor hearts with poor function from young male healthy donors.

We conclude by saying that diminished left ventricular systolic function alone should not be used as a basis for nonutilization. As mentioned, 1300 hearts a year are not being used based exclusively on diminished left ventricular function; $64 \%$ of these hearts had an EF of more than $40 \%$. This represents 785 hearts a year. If only half of these were used, it would represent an increase in the domestic transplant rate of almost $20 \%$.

Moderator. The discussion will be opened by Murray Kwon.

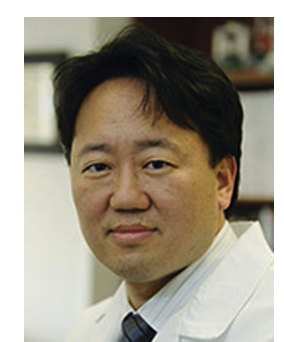

Dr Murray Kwon (Los Angeles, Calif). Your analysis on equivalency and survival among your 5 groups is based on the Kaplan-Meier survival curve, _ yet as you just demonstrated, when you looked at multivariate analysis _ in your group 3 patients, those with $\mathrm{EF}$ of $40 \%$ to $49 \%$ actually had a higher mortality than your normal donors. The survival results you show are predicated on a younger patient population being taken, so what you've actually shown very nicely in your ___ analysis is the risk aversion of the various programs when they take these So, when you cite that $19 \%$ or 1300 hearts are excluded based on dysfunction alone, are you aware of any of the rejected organs from the group of younger donors that you might have actually considered and would actually lead this strategy of accepting compromised donors would actually increase the donor pool in ?

Dr Sibona. Yes, again in the univariate analysis, there are almost no differences in the first 4 groups. The exception is again, group 5, and in the multivariate analysis, we had a higher mortality group. This again represents and reassures what we demonstrate here, that there was probably a selection bias from the surgeons when they were going to procure hearts from younger men; they were probably more prone and more likely to retrieve and procure a heart from a young healthy man, even if the heart had a low EF. So, we're not saying that we should use each heart with an EF of $35 \%$ or $45 \%$, but we said that you should thoroughly evaluate those patients with those hearts and consider them likely for transplantation.

Dr Kwon. Why were there longer hospital stays in group 3 , again the _ $49 \%$ group, that's really what we're targeting in terms of numbers to increase our annual transplantation. Could it be this group experienced higher degrees of primary graft dysfunction, and thus, and so with what we get from the database is important to distinguish what these increased lengths of stay mean. Because death is a broad indicator, and there are other things in life and death that we need to consider.

Dr Sibona. Yes, unfortunately, we don't know why this group had a higher from the database that we use. We only have numbers, and we only have , so everything we can propose now is probably some speculation. Yes, we can propose lower EF had an increased length of stay because they had increased days, so probably they had an increased requirement for pressors or maybe just the surgeons who were transplanting these hearts, and they knew the EF was not optimal they were more reluctant to discharge the patient from the hospital. But again, yes, we only have the numbers from the database 
Dr Kwon. I'm going to shift gears a little bit. Heart transplantation and mechanical circulatory support but during the first of your study, represented $20 \%$ of all transplants That number doubled to $38 \%$ in the latter half of your trial analysis, so our makeup of patients has changed from the very sick patients to relatively stable patients on LVAD support at home, much better-tolerated devices as well. So would you take a compromised donor heart? Or a lower EF heart in this new environment of

Dr Sibona. Yes, so device, we know this evolving technology, we do have some short-term options on ___ and there are actually the ventricular assistive devices are not free of complications. We know that a percent of them are going to have some sort of complication with gastrointestinal bleed, stroke, thrombosis, infections, and so we do still believe that transplants...heart transplantation ___ treatment. The question ___ heart is yes, we should remember that these patients are on end-stage heart failure. They probably cannot get out of bed, even short of breath, they are probably on pressors in the hospital so yes,

Dr Kwon. I'd like to comment that when considering whether I or anyone should heed the recommendations or not, $91 \%$ of programs do less than 30 transplants a year and _ $76 \%$ do less than 20 . The smaller programs won't necessarily have the luxury of 3000 days to see their survival they have 2 or 3 deaths a year, that's

So, I would urge some caution in that regard, but I want to congratulate you and your co-authors for a thoughtful study.

\section{Moderator. Craig.}

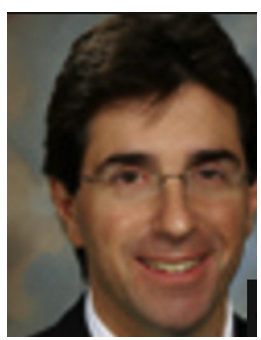

Dr Craig Selzman (Salt Lake City, Utah). There's probably not a more unsatisfying thing to do but to take a stable ambulatory patient and perform a transplant and end up back on an unstable __ more common than... Are you using any $\mathrm{EF}$ or just the last $\mathrm{EF}$ before transplant?
Dr Sibona. Yes, it's the last EF before transplant. Unfortunately, again the database doesn't provide when the EF was recorded. We do know that when a patient is heart, the organism is a hostile environment and probably the heart, it doesn't work as good as it used to work before, but yes, it's the last EF for the patient, but unfortunately, we don't know exactly when the echocardiogram was done.

Dr Selzman. Yeah, it seems like that's important because to your point, brain death roll around and there are certain things that might get better. My follow-up question to that is although you didn't show that the mode of death was different between the groups, did you examine the group that survived and the mode of death. In other words, a patient with multisystem trauma chest versus a cerebral bleed. There's different ways you might assess that patient. Did you look into the individual group survivors and nonsurvivors as to mode of death?

Dr Sibona. We didn't, and it's a good idea for a follow-up study, which did have database, and it has many variables, so we can have obviously that information, but we didn't specifically on each group and differentiate between survivors

Dr Selzman. That might be interesting when you're getting these phone calls at 2:00 AM to

Moderator. Richard, quick question.

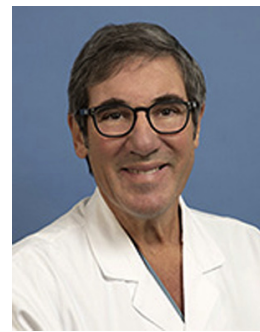

Dr Richard Shemin (Los Angeles, Calif). I'm interested again in the bias of the surgeon in accepting these compromised hearts. In addition to taking young male hearts with low EFs, what about the time of transport in total ischemic time? What was the ultimate $\mathrm{EF}$ of these hearts when the patients

left the hospital?

Dr Sibona. We do have the information for no differences between the groups at all, and we do not have the EF for

Dr Shemin. So, you don't know if the heart has recovered to a near normal EF?

Dr Sibona. No, we mainly focused on the mortality. 